\title{
Efeitos do Tamanho da Classe na Manutenção de Relações de Equivalência em um Delineamento Intra-Grupo ${ }^{1}$
}

\author{
Verônica Bender Haydu \\ Leila Cristina Ferreira Omote \\ Priscila Vicente \\ Natalia Maria Aggio \\ Juliana Barboza Caetano de Paula \\ Universidade Estadual de Londrina
}

\begin{abstract}
RESUMO
Assim como a formação de classes de equivalência, a manutenção destas foi afetada por diversas variáveis experimentais. O presente estudo visou analisar os efeitos do tamanho das classes sobre a formação e a manutenção de classes de estímulos equivalentes com um delineamento intra-grupo. $\mathrm{O}$ procedimento de ensino de escolha-de-acordo-com-modelo foi utilizado para ensinar a 21 estudantes universitários três conjuntos de três classes de estímulos equivalentes compostas por três, quatro e cinco estímulos. A sequência de ensino das classes de diferentes tamanhos foi aleatorizada para controlar o efeito da ordem. Observou-se que essa variável não afetou os resultados. Todos os 21 participantes apresentaram respostas de acordo com as classes treinadas em um Teste Misto realizado depois da aquisição das relações condicionais. Seis semanas após o Teste Misto, a manutenção das relações de equivalência foi testada. Foi observado que 3, 6 e 8 participantes continuaram apresentando porcentagens de acerto acima de $90 \%$ no Teste de Manutenção, quando as classes eram compostas por três, quatro e cinco estímulos, respectivamente. Pode-se concluir que o tamanho das classes não esteve relacionado à formação delas, mas afetou a manutenção das mesmas.
\end{abstract}

Palavras-chave: discriminação condicional; equivalência de estímulos; escolha-de-acordo-com-modelo; estudantes universitários; estabilidade; tamanho de classes.

\begin{abstract}
Class size Effects on the Maintenance of Equivalence Relations With an Intra-Group Design

Like the formation of equivalence classes, their maintenance is affected by diverse experimental variables. The present study aimed to analyze the effect of class size on the formation and maintenance of equivalent stimuli classes with an intra-group design. A matching-to-sample procedure was used to teach to 21 undergraduate students three sets of three equivalent stimuli classes with three, four, and five stimuli. The teaching sequence of the different class's sizes was randomized to control order effects. This variable did not affect the results. All 21 participants showed class consistent responses in a Mixed Test conducted after the conditional relations acquisition. Six weeks after the Mixed Test, the maintenance of the equivalence relations was tested. It was observed that 3,6 and 8 participants continued to show more than $90 \%$ of correct responses on the Maintenance Test, when classes had 3, 4 and 5 stimuli, respectively. It was concluded that class size didn't affect the formation of equivalence classes, but it affected their maintenance.
\end{abstract}

Keywords: conditional discrimination; stimulus equivalence; matching-to-sample; undergraduate students; stability; class size.

O procedimento de escolha de acordo com modelo (matching-to-sample - MTS) tem gerado um amplo conjunto de métodos para análise do fenômeno comportamental denominado "memória". A análise experimental do comportamento de lembrar (expressão mais comumente usada pelos analistas do comportamento) focaliza, predominantemente, o tempo de atraso entre o estímulo-modelo e os estímulos de comparação. Contudo, uma nova direção poderá ser dada a esse tipo de estudo, também dentro de um modelo de 
análise funcional do comportamento, a partir de pesquisas com o modelo da equivalência de estímulos.

A emergência de relações condicionais entre estímulos que não foram diretamente ensinadas, ao serem treinadas no mínimo duas relações com um estímulo em comum, formando classes de equivalência, foi demonstrada por Sidman (1971), Spradlin, Cotter e Baxley (1973), e Sidman e Cresson (1973). Esse modelo tem subsidiado o desenvolvimento e a sistematização de estratégias e tecnologias, que facilitam a aquisição de repertórios, como, por exemplo, ler, escrever e realizar operações aritméticas (e.g., Carmo, Silva, \& Figueiredo, 1999; de Rose, Souza \& Hanna, 1996; Matos, Hubner, Serra, Basaglia \& Avanzi, 2002; Medeiros, Vettorazi, Kliemann, Kurban \& Mateus, 2007; Souza \& Assis, 2005; Stromer, Mackay \& Stoddard, 1992). Além disso, o fenômeno em si tem recebido grande atenção dos analistas do comportamento, conforme pode ser constatado em diversos textos de revisão bibliográfica (e.g., Barros, Galvão, Brino, Goulart \& McIlvane, 2005; de Rose, Kato, Thé \& Kledaras, 1997; Moreira, Todorov \& Nalini, 2006; Sidman, 1994). Nesses artigos, foram especificadas inúmeras variáveis que afetam a formação das relações de equivalência, como, por exemplo, a estrutura de treino; as características dos estímulos; a história pré-experimental dos participantes; o número de estímulos relacionados nas classes de equivalência, entre outras.

O tamanho das classes de equivalência combinado a outras variáveis produziram efeito tanto sobre a emergência das relações de equivalência quanto sobre a formação de novas classes. Por exemplo, Fields e cols. (1997) investigaram a influência do número de nódulos e do tamanho de classes de equivalência estabelecidas previamente sobre a emergência de novas classes por meio da utilização do protocolo simultâneo. Participaram 108 estudantes universitários distribuídos em seis grupos, diferenciados pelas condições de pré-treino, no qual cada grupo foi submetido a um procedimento que levou à formação de classes com diferentes tamanhos. A porcentagem de participantes que apresentou a emergência de novas classes de equivalência esteve diretamente relacionada ao número de nódulos e ao tamanho das classes previamente estabelecidas. Ou seja, uma história experimental de formação de classes maiores facilitou a aprendizagem de novas classes. Em um estudo subsequente, Fields, Hobbie-Reeve, Adams e Reeve (1999) manipularam o tamanho das classes de equivalência e a direcionalidade do treino (CaN - comparison as node e $\mathrm{SaN}-$ sample as node). Classes com cinco e sete membros foram estabelecidas, tendo sido verificado que a porcentagem de participantes que apresentaram emergência de classes de equivalência foi uma função inversa do tamanho da classe.

Além dos estudos que enfocaram o efeito do tamanho das classes sobre a emergência de relações de equivalência, as variáveis que afetam a manutenção desse tipo de comportamento ao longo do tempo têm recebido alguma atenção dos pesquisadores da área (e.g., Haydu \& de Paula, 2005; Rehfeldt \& Dixon, 2005; Rehfeldt \& Dymond, 2005; Saunders, Wachter \& Spradlin, 1988; Spradlin, Saunders \& Saunders, 1992; Wirth \& Chase, 2002). Na maioria desses estudos, foi testado se as classes de equivalência, uma vez formadas, são mantidas em testes realizados algumas semanas ou meses depois, conforme foi feito por Saunders e cols. (1988). Nesse estudo, foi demonstrada a formação e a manutenção de duas classes de equivalência, envolvendo oito estímulos visuais e um estímulo auditivo não-familiares. Foram comparados dois tipos de arranjo de treino: um com o estímulo-modelo como nódulo ( $\mathrm{SaN}$ ) e o outro com o estímulo de comparação como nódulo $(\mathrm{CaN})$. Na Fase 1, foram treinadas as relações condicionais para formar as classes A1B1C1D1E1 e A2B2C2D2E2. Na Fase 2, foram treinadas as relações condicionais para formar as classes A1F1G1H1I1 e A2F2G2H2I2. Essas duas fases permitiram estabelecer relações condicionais entre estímulos com um nódulo (e.g., IA, IF, IG, IH) e relações com dois nódulos (e.g., IB, IC, ID). Após essas duas fases, foram executadas mais duas, sendo que, nas Fases 3 e 4, foi testado com que probabilidade as relações com dois nódulos e as com um nódulo, respectivamente, foram estabelecidas. Um teste de manutenção foi aplicado entre 2 e 5 meses após a Fase 4, no qual se verificou que as classes de estímulos equivalentes com nove membros permaneceram intactas, isto é, foram recordadas sem treino adicional após a sua aquisição e na ausência de prática durante esse período. Apesar de não terem manipulado e avaliado o efeito do número de estímulos relacionados em classes sobre a probabilidade de o comportamento se manter, formularam a seguinte hipótese: quanto mais membros forem relacionados para formar uma classe, mais estáveis se tornam as relações emergentes e novas relações com os membros das classes já formadas podem ser mais facilmente estabelecidas.

Essa hipótese foi retomada por Spradlin e cols. (1992) e formulada nos seguintes termos: em uma classe de estímulos formada por dois membros (por 
exemplo, os estímulos A e B) há somente a relação $\mathrm{AB}$ e sua recíproca; se uma variável qualquer reduzir a força dessas duas relações (AB e BA), a classe inteira será, em decorrência, desfeita. No entanto, se uma classe de estímulos envolver, por exemplo, quatro membros ( $\mathrm{A}, \mathrm{B}, \mathrm{C}$ e $\mathrm{D})$, há uma rede de relações, que inclui $\mathrm{AB}, \mathrm{AC}, \mathrm{AD}, \mathrm{BC}, \mathrm{BD}, \mathrm{CD}$ e suas recíprocas. Portanto, uma dada relação de uma classe com mais do que dois estímulos é multideterminada e apresenta menor suscetibilidade à ação de variáveis que possam desfazê-la.

A hipótese formulada por Saunders e cols. (1988) não foi amplamente investigada por pesquisadores da Análise do Comportamento, sendo uma exceção os estudos desenvolvidos pelo grupo de pesquisa coordenado por Haydu. Esse grupo realizou uma série de experimentos (e.g. Haydu \& de Paula, 2005; Haydu \& Morais, 2005; Rocha \& Haydu, 2002) com diferentes populações, para investigar o efeito do número de estímulos relacionados em classes sobre a probabilidade de formação e de manutenção das relações de equivalência, mantendo constante intra-estudo o número de classes. Em todos esses experimentos, o procedimento empregado para formação de relações foi o MTS e o protocolo de treino foi do simples para o complexo, com expansão gradual das classes e aplicação de testes das relações emergentes depois de cada nova relação treinada, conforme foi descrito por Adams, Fields e Verhave (1993). Os Testes Mistos eram cumulativos, incluindo as relações das etapas anteriores, de tal forma que o último avaliava todas as relações testadas durante o procedimento. Em todos os três experimentos, seis semanas após o último Teste Misto, era realizado um Teste de Manutenção, que era igual ao Teste Misto da última etapa.

Os resultados do primeiro experimento realizado (Rocha \& Haydu, 2002), do qual participaram alunos do Ensino Fundamental ( $\mathrm{n}=18)$, com 9 a 10 anos de idade, indicaram um efeito módico de manutenção das classes maiores. Os 18 participantes foram distribuídos em dois grupos. Para o Grupo 1, as classes a serem formadas eram compostas por três estímulos e para o Grupo 2, seis estímulos, e a estrutura de treino empregada era a CaN. Todos os participantes do Grupo 1 e do Grupo 2 formaram as classes de estímulos equivalentes. Quatro participantes do Grupo 2 e apenas dois do Grupo 1 atingiram o critério no primeiro Teste de Manutenção, ou seja, 50\% mais participantes do Grupo 2 continuaram respondendo de acordo com o treino. Esses resultados levaram o grupo de pesquisa de Haydu a continuar investigando a questão formulada a partir da hipótese de Saunders e cols. (1988) e Spradlin e cols. (1992).

Em um segundo experimento (Haydu \& Morais, 2005), não foi possível identificar o efeito do tamanho das classes de equivalência sobre sua formação e manutenção, mas sim sobre a recuperação de relações enfraquecidas. Participaram mulheres adultas e da terceira idade com 56 a 75 anos, as quais foram distribuídas em dois grupos com nove participantes cada, sendo que a única diferença no procedimento desses grupos era a sequência de treino. As participantes foram submetidas a treinos para formar seis classes com quatro e seis classes com seis estímulos, com a estrutura de treino LIN - séries-lineares. Ao Grupo 1 foram ensinadas, primeiro, as classes com quatro estímulos e ao Grupo 2, as classes com seis estímulos. Das 18 participantes, 15 formaram as classes de equivalência com seis estímulos e 16 formaram classes com quatro estímulos, sendo que uma proporção relativamente igual apresentou manutenção do comportamento de acordo com as classes especificadas pelas experimentadoras: 10 de 15 apresentaram manutenção das classes com seis estímulos e 11 de 16 apresentaram manutenção das classes com quatro estímulos. Portanto, não houve efeito do tamanho das classes de estímulos tanto na formação quanto na manutenção das relações de equivalência. No entanto, houve um aumento no número de relações recuperadas ao longo do Teste de Manutenção quando as classes eram compostas por seis estímulos, mas não quando eram compostas por quatro estímulos. Além disso, deve-se considerar que, pelo fato de ter sido usada a estrutura de treino LIN, o número de nódulos era maior quando as classes eram formadas por um maior número de estímulos, sendo, portanto, a tarefa mais complexa (ver Fields e cols., 1999), o que pode ter prejudicado a observação do efeito da variável experimental.

O efeito do tamanho das classes sobre a probabilidade de manutenção de relações de equivalência também não pôde ser observado no estudo desenvolvido por Haydu e de Paula (2005). Neste estudo, foi usada a estrutura de treino $\mathrm{CaN}$ para controlar a variável distância nodal. Vinte e quatro estudantes universitários, com 18 a 21 anos de idade, foram distribuídos em quatro grupos, os quais foram submetidos ao procedimento de treino de três classes de equivalência com três, quatro, cinco ou seis estímulos por classe, dependendo do grupo. Todos os participantes formaram classes de equivalência. No Teste de Manutenção, 
a porcentagem de relações que estavam de acordo com as classes previamente estabelecidas não foi afetada pelo tamanho destas, mas um maior número de erros ocorreu em tentativas que envolviam as relações ensinadas por último. A explicação fornecida pelas pesquisadoras foi a de que, sendo realizados testes a cada nova relação treinada, as primeiras relações ensinadas eram testadas um número maior de vezes do que as últimas. Com isso, a repetição dos testes pode ter funcionado como uma forma de "retreino", mesmo tendo sido feitos sob contingência de extinção, o que está de acordo com o que foi proposto por Rehfeldt e Root (2004).

Nos estudos de Rocha e Haydu (2002), Haydu e Morais (2005) e Haydu e de Paula (2005), variáveis não controladas podem ter contribuído para que um possível efeito do tamanho das classes de estímulos equivalentes sobre a manutenção destas não tivesse sido observado. Além disso, considerando que esse fenômeno é sensível a diversas características de procedimento e que pode estar relacionado a variáveis da história experimental dos participantes, mais estudos sobre o tema, com maior controle de variáveis estranhas são necessários. Devido a esses aspectos, planejou-se um estudo com um delineamento intra-grupo, em que classes de diferentes tamanhos foram ensinadas a cada participante e a variável número de tentativas de teste de cada relação foi controlada. Do mesmo modo como nos estudos realizados por Rocha e Haydu (2002), Haydu e Morais (2005), Haydu e de Paula (2005), o período de seis semanas de intervalo entre o último Teste Misto e o Teste de Manutenção foi adotado para aumentar a probabilidade de haver retorno dos participantes. Em outros estudos que testaram a manutenção de classes de estímulos equivalentes, esse período variou de 1 a 5 meses (Rehfeldt \& Dymond, 2005; Rehfeldt \& Root, 2004; Saunders e cols., 1988; Wirth \& Chase, 2002). Diversos aspectos do procedimento, como a estrutura de treino $\mathrm{CaN}$, o protocolo de treino do simples para o complexo e a expansão gradual das classes foram iguais aos do estudo de Haydu e de Paula (2005), além de se controlar a variável número de tentativas de teste que afetou os resultados e dificultou a verificação do possível efeito do número de membros por classe. Portanto, o objetivo do presente estudo foi investigar se e como o número de estímulos relacionados em classes de equivalência afeta a formação e a manutenção destas classes.

\section{MÉTODO}

\section{Participantes}

Os alunos do $1^{\circ}$ ano de um curso de Psicologia foram convidados a participar da pesquisa. Dentre os interessados, foram sorteados 24 . A idade dos participantes variou entre 18 e 21 anos. Nenhum deles havia participado anteriormente de experimentos na área da Análise do Comportamento e não haviam tido aulas sobre o tema equivalência de estímulos.

\section{Materiais e situação experimental}

A coleta de dados foi realizada em sessões individuais, em duas salas contendo uma mesa, uma cadeira e um microcomputador Pentium. Um software, que permite a programação, aplicação e registro de tentativas de escolha de acordo com modelo, foi usado para a coleta de dados. O software apresenta, de forma simultânea, o estímulo-modelo ao centro e os estímulos de comparação distribuídos horizontalmente na porção inferior da tela, quando são programados três estímulos de comparação. Consequências diferenciais na forma de texto, sons ou imagens podem ser programados, mas não o intervalo entre tentativas. Os estímulos usados no pré-treino foram letras do alfabeto arábico e, nas demais fases, figuras não-familiares desenhadas com base nas figuras do estudo de Spencer e Chase (1996).

\section{Procedimento}

A coleta de dados foi iniciada após a leitura e assinatura, pelos participantes, do Termo de Consentimento Livre e Esclarecido aprovado pelo Comitê de Ética da instituição das autoras. No início da primeira sessão, os participantes foram informados de que o estudo seria sobre a recordação de eventos e que eles resolveriam tarefas que envolviam responder a relações entre estímulos. A principal variável independente do estudo foi controlada pelo delineamento experimental intra-grupo, tendo se submetido todos os participantes ao treino de todos os diferentes tamanhos de classes. Para controlar o efeito da ordem em que as classes de diferentes tamanhos foram ensinadas, os participantes foram distribuídos em seis grupos com quatro em cada um, sendo que seis diferentes sequências de distribuição dos tamanhos de classes foram programadas conforme pode ser observado na Tabela 1. 
TABELA 1

Distribuição das Sequências das Diferentes Quantidades de Estímulos por Classes para cada Grupo

\begin{tabular}{lcccccc}
\hline & \multicolumn{5}{c}{ Distribuição das sequências por grupo } \\
& Grupo 1 & Grupo 2 & Grupo 3 & Grupo 4 & Grupo 5 & Grupo 6 \\
\hline No de estímulos & 3 & 4 & 5 & 3 & 4 & 5 \\
por classe & 4 & 3 & 4 & 5 & 5 & 3 \\
& 5 & 5 & 3 & 4 & 3 & 4 \\
\hline
\end{tabular}

TABELA 2

Distribuição da Sequência de Etapas, Fases e Blocos e Indicação das Relações Envolvidas e Número de Tentativas (№ t.) para Cada Conjunto

\begin{tabular}{|c|c|c|c|c|c|c|c|c|}
\hline \multirow{2}{*}{ Etapas } & \multirow{2}{*}{ Fases } & \multirow[t]{2}{*}{ Blocos } & \multicolumn{2}{|c|}{$\begin{array}{l}\text { Conjunto com três } \\
\text { estímulos por classe }\end{array}$} & \multicolumn{2}{|c|}{$\begin{array}{l}\text { Conjunto com quatro } \\
\text { estímulos por classe }\end{array}$} & \multicolumn{2}{|c|}{$\begin{array}{l}\text { Conjunto com cinco } \\
\text { estímulos por classe }\end{array}$} \\
\hline & & & Relações & $\mathrm{N}^{0} \mathrm{t}$. & Relações & $\mathrm{N}^{0} \mathrm{t}$. & Relações & $\mathrm{N}^{0} \mathrm{t}$. \\
\hline \multirow{22}{*}{ Etapa 1} & \multirow{10}{*}{ Fase1 } & 1-Treino & BA & 18 & ED & 18 & $\mathrm{IH}$ & 18 \\
\hline & & 2-Treino & BA & 18 & ED & 18 & $\mathbb{H H}$ & 18 \\
\hline & & 3-Teste LB/Sim & $\mathrm{BA}, \mathrm{AB}$ & 18 & $\mathrm{ED}, \mathrm{DE}$ & 18 & $\mathrm{IH}, \mathrm{HI}$ & 18 \\
\hline & & 4-Teste LB/Sim & $B A, A B$ & $0+54$ & $\mathrm{ED}, \mathrm{DE}$ & $0+36$ & $\mathrm{IH}, \mathrm{HI}$ & $0+18$ \\
\hline & & 5-Treino & $\mathrm{CA}$ & 18 & FD & 18 & JH & 18 \\
\hline & & 6-Treino & $\mathrm{CA}$ & 18 & FD & 18 & JH & 18 \\
\hline & & 7-Teste LB/Sim & $\mathrm{CA}, \mathrm{AC}$ & 18 & $\mathrm{FD}, \mathrm{DF}$ & 18 & $\mathrm{JH}, \mathrm{HJ}$ & 18 \\
\hline & & 8-Teste LB/Sim & $\mathrm{CA}, \mathrm{AC}$ & 54 & $F D, D F$ & 36 & $\mathrm{JH}, \mathrm{HJ}$ & 18 \\
\hline & & 9-Teste Equiv. & $\mathrm{BC}, \mathrm{CB}$ & $18+54$ & $\mathrm{EF}, \mathrm{FE}$ & $18+36$ & IJ, Jl & $18+18$ \\
\hline & & 10-Teste Misto & $\mathrm{BA}, \mathrm{CA}, \mathrm{BC}$ & 54 & $\mathrm{ED}, \mathrm{FD}, \mathrm{EF}$ & 54 & $\mathrm{IH}, \mathrm{JH}, \mathrm{IJ}$ & 54 \\
\hline & \multirow{6}{*}{ Fase2 } & 11-Treino & - & - & GD & 18 & $\mathrm{KH}$ & 18 \\
\hline & & 12-Treino & - & - & GD & 18 & $\mathrm{KH}$ & 18 \\
\hline & & 13-Teste LB/Sim & - & - & $\mathrm{GD}, \mathrm{DG}$ & 18 & $\mathrm{KH}, \mathrm{HK}$ & 18 \\
\hline & & 14-Teste LB/Sim & - & - & $\mathrm{GD}, \mathrm{DG}$ & 54 & $\mathrm{KH}, \mathrm{HK}$ & 36 \\
\hline & & 15-Teste Equiv. & - & - & GE, EG, GF, FG & $36+108$ & $\mathrm{KI}, \mathrm{IK}, \mathrm{KJ}, \mathrm{JK}$ & $36+72$ \\
\hline & & 16-Teste Misto & - & - & $\mathrm{ED}, \mathrm{FD}, \mathrm{EF}, \mathrm{GD}, \mathrm{GE}, \mathrm{GF}$ & 108 & $\mathrm{IH}, \mathrm{JH}, \mathrm{IJ}, \mathrm{KH}, \mathrm{KI}, \mathrm{KJ}$ & 108 \\
\hline & \multirow{6}{*}{ Fase3 } & 17-Treino & - & - & - & - & LH & 18 \\
\hline & & 18-Treino & - & - & - & - & LH & 18 \\
\hline & & 19-Teste LB/Sim & - & - & - & - & $\mathrm{LH}, \mathrm{HL}$ & 18 \\
\hline & & 20-Teste LB/Sim & - & - & - & - & $\mathrm{LH}, \mathrm{HL}$ & 54 \\
\hline & & 21-Teste Equiv. & - & - & - & - & LI, IL, LJ, JL, LK, KL & $54+162$ \\
\hline & & 22-Teste Misto & - & - & - & - & $\begin{array}{l}\mathrm{IH}, \mathrm{JH}, \mathrm{IJ}, \mathrm{KH}, \mathrm{KI}, \mathrm{KJ} \text {, } \\
\mathrm{LH}, \mathrm{LI}, \mathrm{LJ}, \mathrm{LK}\end{array}$ & 180 \\
\hline Etapa 2 & & 23-Teste Man & $\mathrm{BA}, \mathrm{CA}, \mathrm{BC}$ & 54 & $\mathrm{ED}, \mathrm{FD}, \mathrm{EF}, \mathrm{GD}, \mathrm{GE}, \mathrm{GF}$ & 108 & $\begin{array}{l}\mathrm{IH}, \mathrm{JH}, \mathrm{IJ}, \mathrm{KH}, \mathrm{KI}, \mathrm{KJ} \text {, } \\
\mathrm{LH}, \mathrm{LI}, \mathrm{LJ}, \mathrm{LK}\end{array}$ & 180 \\
\hline
\end{tabular}

Nota. O sinal de adição indica que o número colocado após ele corresponde à quantidade de tentativas acrescentadas para garantir o mesmo número de tentativas entre as diferentes relações e fases, sendo a soma destes o número total de tentativas do bloco. Por questão de espaço, nos Testes Mistos e Man., as relações simétricas não foram incluídas na tabela, mas elas também pertenciam a esses blocos. 
Cada sessão teve a duração máxima de 50 minutos, variando de acordo com o número de blocos que o participante repetia. A estrutura de treino empregada foi a $\mathrm{CaN}$ e os participantes foram submetidos ao procedimento de escolha de acordo com o modelo arbitrário para formação dos três conjuntos de classes com três, quatro e cinco estímulos. Nas tentativas com apresentação de consequências diferenciais, a escolha do estímulo de comparação correto (o que estava de acordo com as contingências experimentalmente estabelecidas) era seguida pela mensagem: "Parabéns, você acertou"; e a escolha dos estímulos incorretos, por: "Que pena, você errou". Para passar para a tentativa seguinte, o participante tinha que clicar sobre a mensagem. Nos blocos sem consequências, a escolha de qualquer estímulo era seguida pelo desaparecimento de todos os estímulos da tentativa e pela apresentação dos estímulos da tentativa seguinte.

A todos os participantes foram ensinadas relações condicionais que possibilitavam a formação de três conjuntos com três classes cada um, sendo um deles formado por classes com três membros (Conjunto com três estímulos por classe), o outro por classes com quatro membros (Conjunto com quatro estímulos por classe) e um terceiro por classes com cinco membros (Conjunto com cinco estímulos por classe). O procedimento de ensino e teste das relações condicionais de cada conjunto (sumariado na Tabela 2) foi dividido em duas etapas intercaladas por uma semana de intervalo. A Etapa 1 envolvia três fases distintas: na primeira, foram formadas classes com três estímulos; na segunda, um novo membro foi acrescentado a cada classe; e na terceira, foi adicionado mais um estímulo por classe. $\mathrm{O}$ treino do conjunto com três estímulos por classe envolveu apenas a Fase 1, o do conjunto com quatro estímulos por classe envolveu as Fases 1 e 2 e o do conjunto com cinco estímulos por classe envolveu as Fases 1, 2 e 3. Cada fase foi composta por: Treino das Relações Condicionais (Treino), Testes de Linha de Base e de Simetria (Teste LB/Sim), Teste de Equivalência (Teste Equiv.) e Teste Misto. Em todos os blocos, com exceção do Pré-treino (realizado antes da Fase 1), havia um critério de $90 \%$ de acerto exigido para a passagem para o bloco seguinte. Na Etapa 2, era feito o Teste de Manutenção (Teste Man.), no qual não havia exigência de acertos e cada bloco era apresentado apenas uma vez, independentemente do desempenho do participante.

A Etapa 1 iniciava com o Pré-treino, que não consta na Tabela 2, realizado com a finalidade de familiarizar os participantes com o MTS, no qual o critério de encerramento era de $100 \%$ de acerto. Após o Pré-treino, foi iniciado o procedimento da Fase 1 de um dos três conjuntos de acordo com o grupo (ver sequência na Tabela 1). Na Tabela 2, está especificada a distribuição das etapas, as fases e os blocos, com a identificação das relações treinadas e testadas e o número de tentativas de cada conjunto. Os traços indicam que aquela fase não estava presente. Foram programadas tentativas adicionais nos Testes LB/Sim. e nos Testes Equiv., cuja quantidade está explicitada, na Tabela 2, após o sinal de adição. Essas tentativas adicionais visaram balancear o número mínimo de tentativas de testes dos diferentes tipos de relações para todos os conjuntos. Em todos os blocos, as tentativas foram sequenciadas aleatoriamente, mas sendo cada uma apresentada uma vez, antes de ser repetida. Os estímulos de comparação eram aleatorizados nas três possíveis posições da tela.

A Fase 1 era iniciada com o bloco de treino das relações condicionais com $100 \%$ de feedback. Todos os blocos de treino eram compostos por 18 tentativas, que correspondem a seis apresentações de cada relação. Tendo sido atingido o critério de acerto, o procedimento seguia para o Bloco 2, caso contrário, permanecia no Bloco 1 até que o participante o atingisse. $\mathrm{O}$ Bloco 2 era composto pelas mesmas tentativas do Bloco 1, mas com 50\% de feedback. Quando o participante atingia o critério neste bloco, o procedimento passava para o Bloco 3 e, se não atingisse, retornava ao Bloco 1. Todas as vezes em que o procedimento retornava, ele era reiniciado a partir daquele ponto. No Bloco 3, foram programadas nove tentativas de teste de linha de base distribuídas entre as nove tentativas de teste das relações de simetria, de forma que cada relação era apresentada três vezes, totalizando 18 tentativas. Nenhuma consequência foi programada para esse e os demais testes. Quando o participante não atingia o critério de acerto neste bloco, o procedimento voltava para o Bloco 2. O Bloco 4 era um Teste de LB/Sim, que tinha um número diferente de tentativas de acordo com o conjunto, conforme pode ser observado na Tabela 2. A porcentagem de acerto abaixo do critério de $90 \%$ no Bloco 4 era condição para que o Bloco 2 fosse reapresentado.

Ainda na Fase 1, os Blocos 5 e 6 envolviam o treino de uma nova relação, e os Blocos 7 e 8, o correspondente Teste de LB/Sim. Esses blocos tinham as mesmas características dos blocos iniciais de treino (Blocos 1 e 2) e de teste (Blocos 3 e 4) respectivamente. A diferença foi o bloco de retorno: no Bloco 5 não havia retorno a blocos anteriores, sendo repetido 
até o alcance do critério; no Bloco 6 , o procedimento retornava ao Bloco 5; nos Blocos 7 e 8 , o retorno era para Bloco 6. No Bloco 9, era feito o Teste de Equiv. Se o participante não atingisse o critério de acerto nesse bloco, o procedimento voltava ao Bloco 1 e era reiniciado. Se atingisse, passava para o Bloco 10 (Teste Misto). No Bloco 10 eram apresentadas todas as relações até então testadas e quando o critério de acerto não era alcançado nesse bloco, o procedimento retornava para o Bloco 1. A Fase 1 era encerrada no Bloco 10 e seguida pela Fase 2 no treino dos conjuntos com quatro estímulos por classe e no treino dos conjuntos com cinco estímulos por classe. A Fase 3 era iniciada com o Bloco 17 no treino do conjunto com cinco estímulos por classe. Após o término das fases de um dado conjunto, um novo conjunto era treinado, conforme a sequência indicada na Tabela 1 .

A partir do Bloco 11 até o 22, uma nova relação era treinada e testada, obedecendo a mesma sequência de blocos e critérios descritos para os treinos e testes das relações anteriores. Quando o critério de acerto não era atingido em um bloco de treino, o retorno era feito ao correspondente treino com $100 \%$ de feedback; nos Testes LB/Sim. o retorno era feito para o respectivo treino com $50 \%$ de feedback; e nos Testes de Equiv. e Misto o retorno era feito ao Bloco 1. Ao finalizar os três conjuntos, na sequência prevista pelo grupo em que o participante estava inserido, ele era informado do término da primeira etapa e convidado a retornar após um período de 6 semanas.

Na Etapa 2, era realizado o Teste de Man. de cada conjunto, sucessivamente, sem intervalos, na ordem estabelecida para o grupo ao qual o participante pertencia (ver Tabela 1). A forma de apresentação dos estímulos, os estímulos utilizados (modelo e comparação), o número de tentativas e as instruções apresentadas foram idênticos aos do último Teste Misto de cada conjunto. Independentemente do desempenho do participante, depois de concluir esta etapa, ele era informado sobre o término de sua participação no experimento.

\section{RESULTADOS}

Dos 24 participantes iniciais da pesquisa, foram considerados para análise os dados de 21 que concluíram todas as fases do procedimento. Os participantes foram identificados por números, de acordo com o grupo: Grupo $1(11,12,13,14)$, Grupo 2 (21, 22, 23, 24), Grupo $3(31,32,33)$, Grupo $4(41,42,43)$, Grupo $5(51,52,53,54)$, Grupo $6(61,62,63)$. Para avaliar o efeito da ordem de realização dos conjuntos com classes de diferentes tamanhos foi utilizado o Teste Kruskal-Wallis, o qual revelou não haver diferença estatisticamente significativa $(p>0,05)$ entre os grupos. Esse resultado permitiu que a análise dos dados fosse feita independentemente da ordem em que as classes de diferentes tamanhos foram ensinadas. Ou seja, os resultados foram tratados como se não houvesse grupos.

A Figura 1 apresenta o índice de repetição dos blocos de treino e dos Testes de LB/Sim. e de Equiv. de cada participante, calculado a partir da divisão do número total de repetições pelo número mínimo necessário em cada conjunto de blocos. Nesta figura, são apresentados 18 gráficos, reunidos em três colunas de acordo com o número de membros por classe de cada conjunto. A primeira, segunda e terceira colunas correspondem, respectivamente, aos conjuntos com três, quatro e cinco estímulos por classe. Na última linha, é apresentado o índice médio geral de repetições, incluindo fases de treino e de teste.

Verifica-se, na Figura 1, que para oito participantes nos conjuntos com três estímulos $(11,12,13,14,33$, 41, 52 e 53), cinco participantes nos conjuntos com quatro estímulos $(21,24,41,42,63)$ e seis participantes nos conjuntos com cinco estímulos $(24,31,32$, $33,61,62)$, o índice de repetição dos treinos da primeira relação ensinada foi maior que dos demais treinos. Índices médios de repetição iguais ou superiores a 2,0 são observados no caso de cinco, três e nove, dos 21 participantes quando as classes formadas eram compostas por três, quatro e cinco estímulos respectivamente. Além disso, verifica-se que os participantes que apresentaram os mais altos índices de repetição no treino do conjunto com três estímulos (por exemplo, da relação BA - Participantes 11, 12 e 13) não são os mesmos que apresentaram índices mais altos de repetição dos conjuntos com quatro estímulos (relação ED - participantes 21, 24 e 63) e cinco estímulos (relação $\mathrm{JH}$ - Participantes 24, 31, 32, 33, 52, 53, 54, 61, 62 e 63).

Observa-se, ainda, na Figura 1 que respectivamente, dois (43 e 61), três $(14,24$ e 63$)$ e nove $(23,24$, $31,32,33,52,54,61$ e 63$)$ participantes precisaram repetir Testes de Equiv. no treino dos conjuntos com três, quatro e cinco estímulos por classe. Entretanto, não se verifica uma relação entre índice de repetição médio e porcentagem de acerto no Teste Man. (ver Figura 2). Por exemplo, o P31 atingiu o critério especificado, com $97,7 \%$ de acerto, no treino do conjunto com cinco estímulos, em que seu índice médio de 
repetição foi o maior $(2,5)$ em comparação aos índices de repetição de 1,3 e 1,2 nos blocos com três e quatro estímulos, respectivamente. O P13 atingiu critério especificado, com 98, 3\% de acerto, no treino do conjunto com cinco estímulos, em que o índice de repetição por ele apresentado foi o menor $(1,2)$ em comparação ao índice de repetição dos blocos com três e quatro estímulos (2,9 e 1,3, respectivamente). $\mathrm{O}$ P14 apresentou a menor porcentagem de acerto (64,8\% de acerto) no treino do conjunto com quatro estímulos, em que o índice de repetição dos blocos foi o maior $(2,2)$ em comparação ao índice de repetição dos blocos dos conjuntos com três e cinco estímulos (1,5 e 1,8, respectivamente). O P54 apresentou o menor índice de acerto no treino do conjunto com três estímulos (48\% de acertos) em que repetiu, proporcionalmente, um menor número de vezes os blocos $(1,1)$ em comparação ao conjunto com quatro estímulos $(1,5)$ e ao conjunto com cinco estímulos $(1,8)$. Além disso, no treino de todos os conjuntos, um mesmo índice de repetição está relacionado às percentagens mais baixas de acerto (abaixo de $40 \%$ de acertos) e às porcentagens mais altas de acerto (acima de 90\%) no Teste Man. (índices 1,$3 ; 1,3 ; 1,7$ respectivos ao treino dos conjuntos com três, quatro e cinco estímulos).

A Figura 2 apresenta a porcentagem de acerto e o tempo médio de reação das respostas de escolha de cada participante no último Teste Misto e no Teste de Manutenção. Estes resultados são apresentados em 12 gráficos distribuídos em três colunas e quatro linhas. As colunas reúnem os dados de cada conjunto com um número específico de estímulos por classe; as duas primeiras linhas referem-se à porcentagem de acerto e as duas últimas, ao tempo médio de reação. Verifica-se, na Figura 2, que as porcentagens de acerto de todos os participantes no Teste Misto são superiores a $90 \%$ e que no Teste Man. do conjunto com três estímulos por classe, para três participantes $(21,32$ e 61$)$, as porcentagens são superiores a $90 \%$ e, para outros dois participantes (31 e 41), as porcentagens são próximas a $90 \%$ (87\% nos dois casos). Os demais participantes apresentaram porcentagens inferiores a $80 \%$. Ainda neste teste, no conjunto com quatro estímulos por classe, para sete participantes $(12,13,21,23,53$, 54 e 62), as porcentagens de acerto são iguais ou superiores a $90 \%$, sendo inferiores a $80 \%$ no caso dos demais participantes. No Teste Man. do conjunto com cinco estímulos por classe, para oito participantes (11, $12,13,14,21,31,32$ e 33), as porcentagens de acerto são superiores a $90 \%$, sendo inferiores a $80 \%$ no caso dos demais participantes. Apenas no caso do Participante 21, as porcentagens de acerto são superiores a $90 \%$ no treino de todos os três conjuntos. A análise estatística com base nas porcentagens de acerto, feita por meio do Teste de Friedman, indicou haver diferença estatisticamente significante $(\mathrm{p}<0,05)$ intra-grupo. Na comparação dos pares (Dunn's Multiple Comparisions Test), houve diferença estatisticamente significante na porcentagem de acerto do conjunto com três estímulos por classe e do conjunto com cinco estímulos por classe $(p<0,05)$, mas não entre os demais pares.

Ao se analisar as duas últimas linhas da Figura 2, verifica-se que, para a maioria dos participantes, os tempos de reação médios, no Teste Man., são maiores do que no Teste Misto. A análise estatística feita por meio do Teste de Friedman revelou diferença estatisticamente significativa $(\mathrm{p}<0,05$ e $\mathrm{F}=35.982)$. Na comparação do pares feita por meio do Dunn's Multiple Comparisons Test, verificou-se diferenças estatisticamente significantes entre os tempos de reação médios dos participantes no Teste Misto e no Teste Man. do conjunto com três estímulos por classe e do conjunto com quatro estímulos por classe, mas não do conjunto com cinco estímulos por classe. A comparação entre o tempo de reação com a porcentagem de respostas corretas, no Teste Man., feita por meio do Teste de Correlação de Spearman, revelou que não houve correlação entre os dados. No entanto, a inspeção visual destes dados permite observar que no caso de 14 dos 21 participantes, os tempos de reação são maiores no conjunto em que houve menor porcentagem de acerto. Por exemplo, nas informações referentes a P1 constata-se $66,6 \%, 72,2 \%$ e $93,8 \%$ de tentativas corretas quando a condição experimental exigia a formação de classes com três, quatro e cinco estímulos, respectivamente. $\mathrm{Na}$ formação de classes com três estímulos, verifica-se o maior tempo de reação de P1, em comparação à formação ao das classes com quatro e cinco estímulos. Observa-se, ainda, que os dados de 20 dos 21 participantes são inferiores ao critério de $90 \%$ de acerto na formação do conjunto em que apresentaram o maior tempo de reação. Além disso, considerando apenas os dados dos 11 participantes que atingiram o critério na formação de classes de pelo menos um conjunto (P21 não entra nesta análise porque atingiu o critério em todos os conjuntos), verifica-se que os menores tempos de reação de 9 desses 11 participantes foram apresentados na condição em que atingiram o critério de $90 \%$ de acerto. 
Conjunto com três estímulos por classe
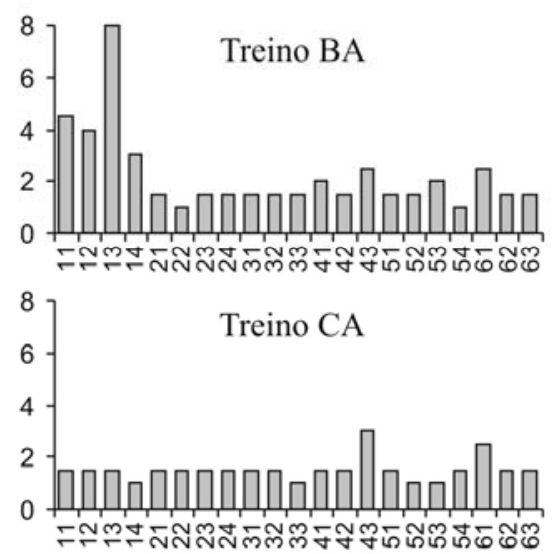

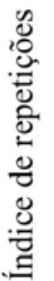
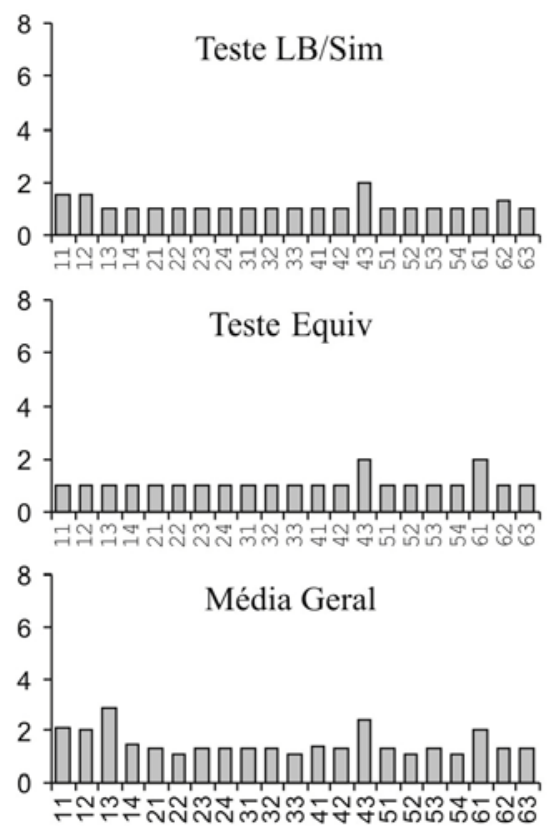

Conjunto com quatro

estímulos por classe
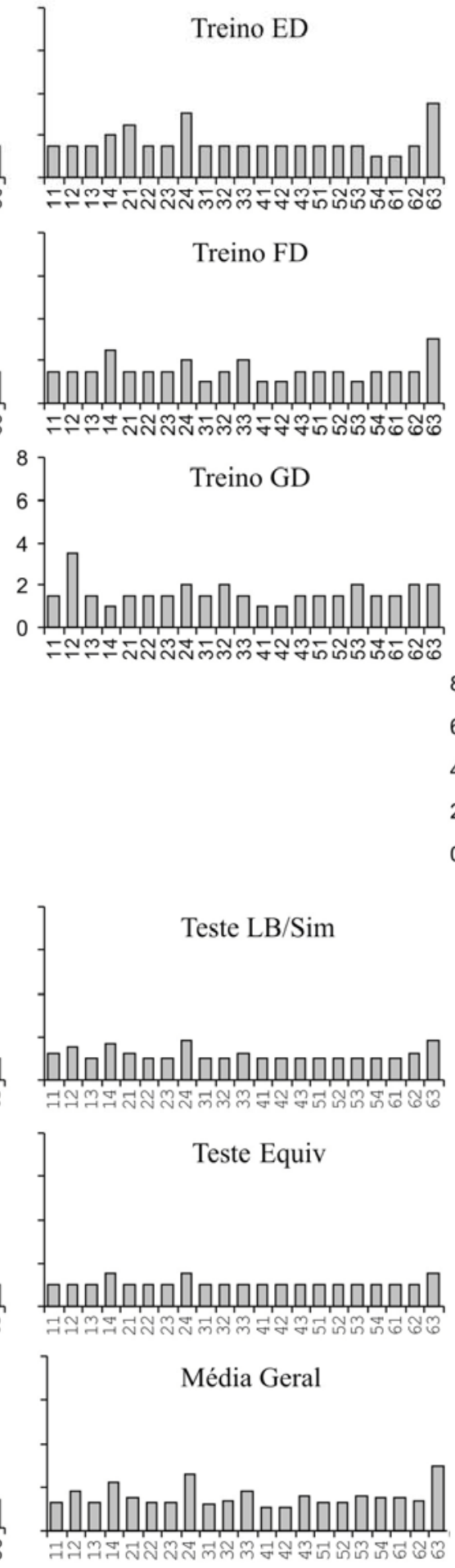

Participantes
Conjunto com cinco

estímulos por classe
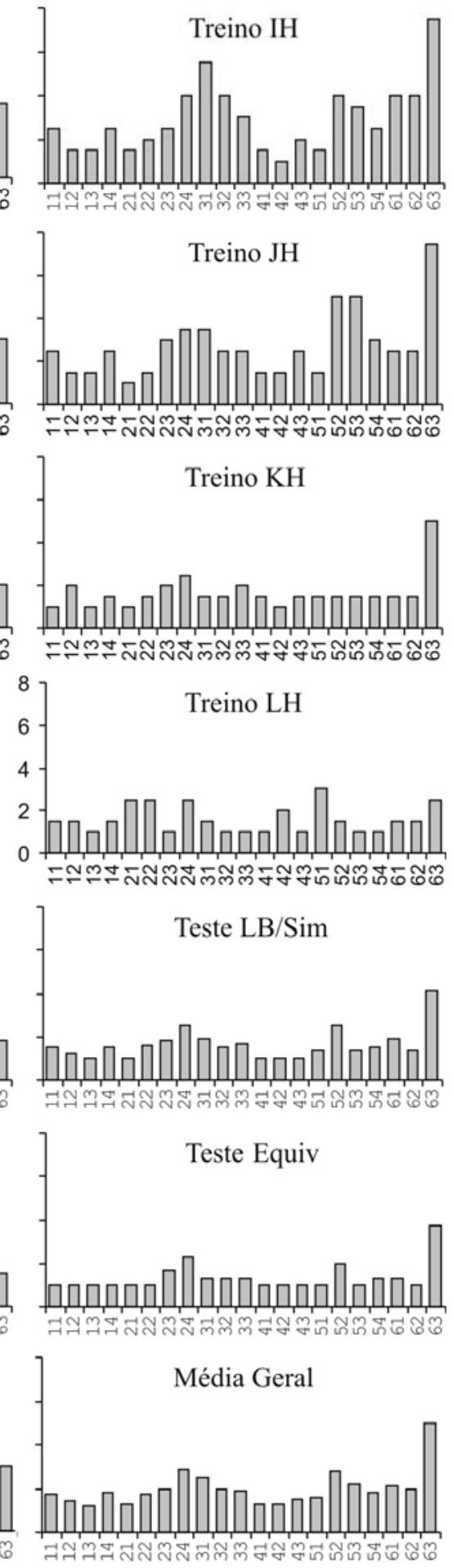

Figura 1. Índice de repetição de cada participante nos blocos de treino e de Testes de LB/Sim. e de Equiv. dos conjuntos com três, quatro e cinco estímulos por classe, e média geral de treinos e testes. 
Teste Misto $\square$ Teste de Manutenção
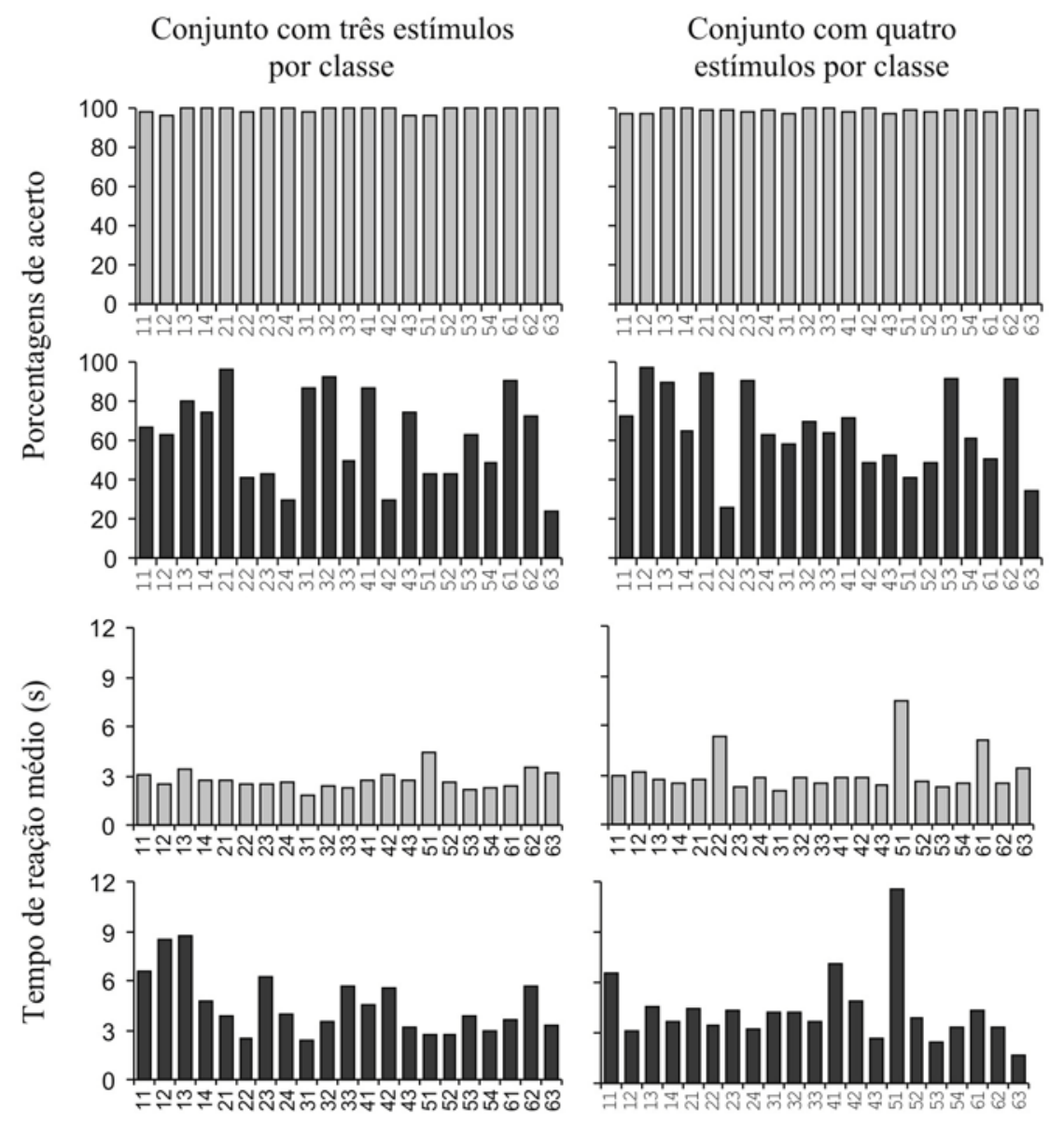
Conjunto com cinco estímulos por classe
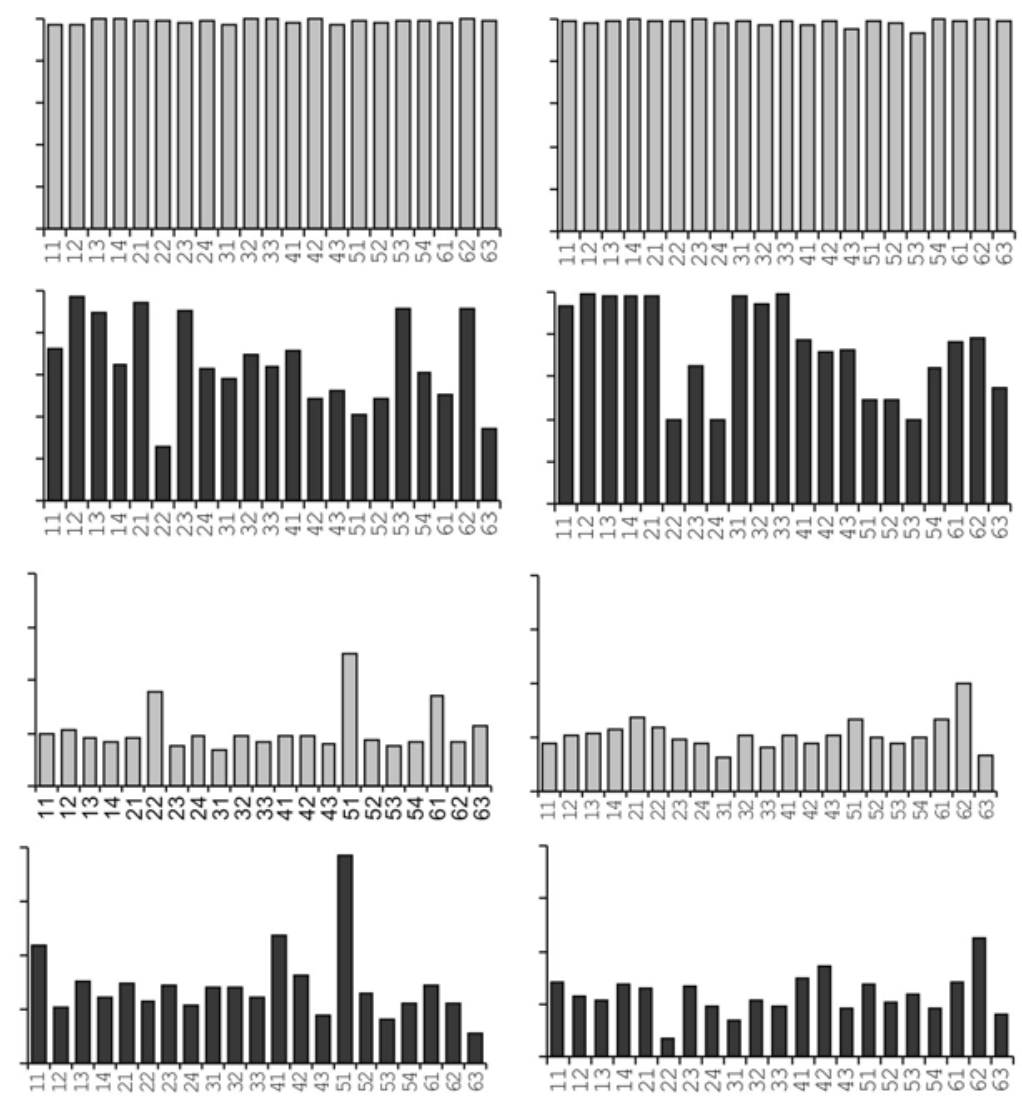

Participantes

Figura 2. Representação percentual de acertos e de tempo de reação médio das respostas de escolha em segundos de cada participante no Teste Misto e no Teste de Manutenção do conjunto com três estímulos por classe, do conjunto com quatro estímulos por classe e do conjunto com cinco estímulos por classe. 
Linha de base $\square$ Simetria $\quad$ Equivalência

Conjunto com três estímulos por classe
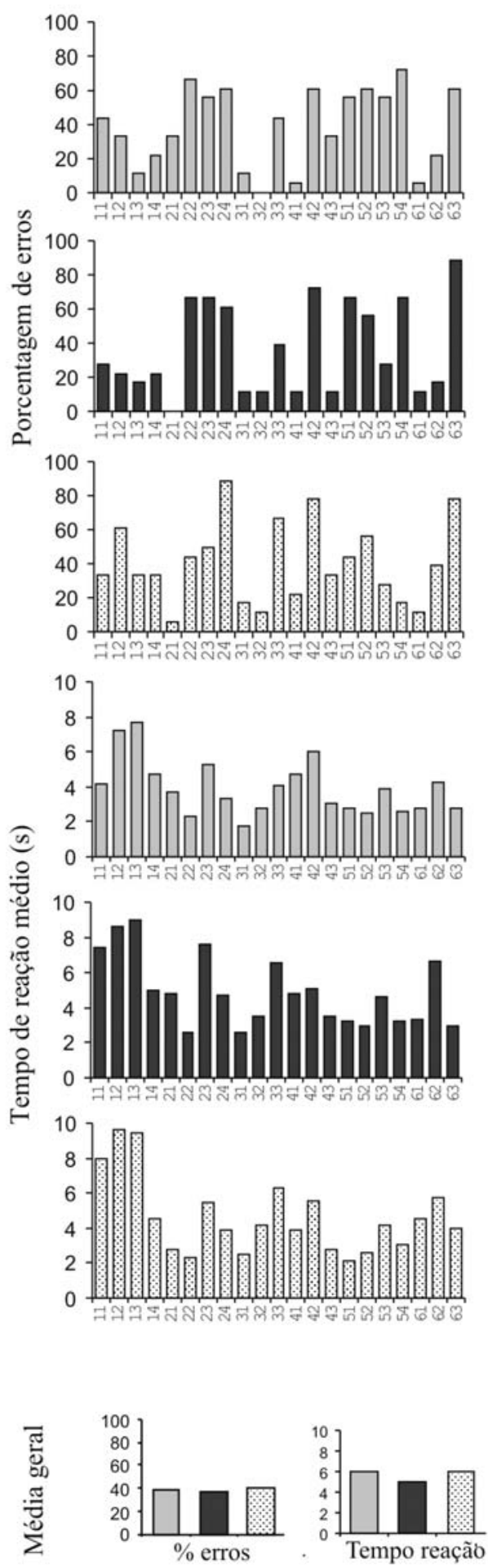

Conjunto com quatro

estímulos por classe
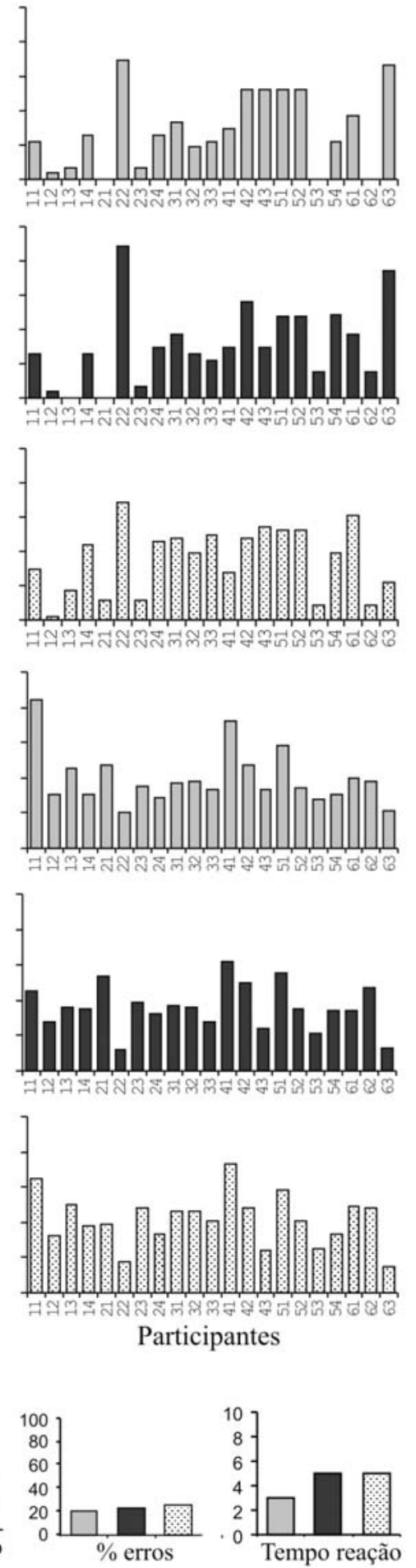

Conjunto com cinco estímulos por classe
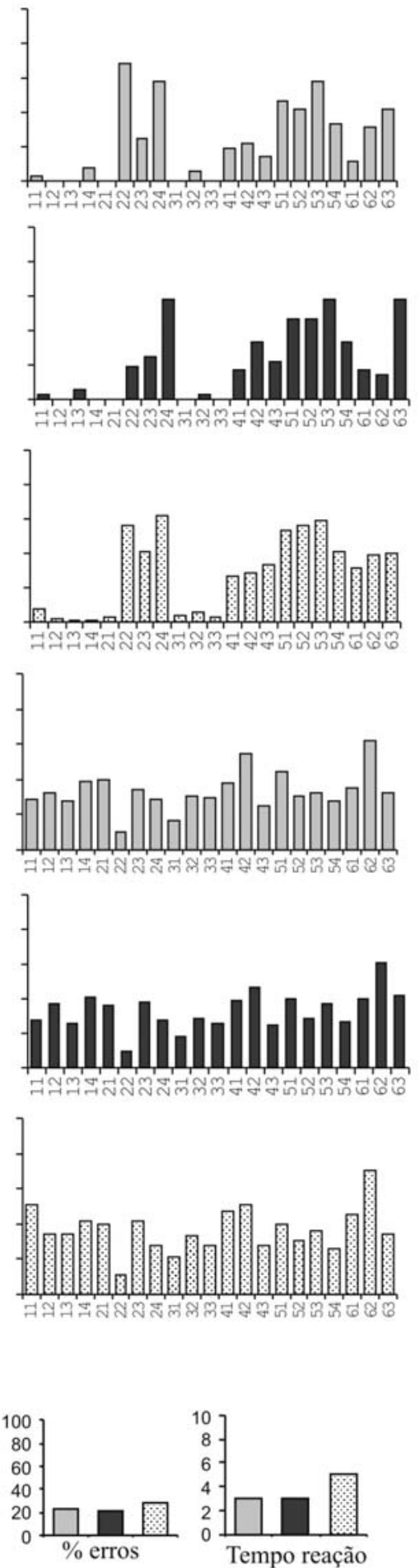

Figura 3. Representação percentual de erros e dos tempos de reação médios das respostas de escolha em segundos no do Teste de Manutenção do conjunto com três estímulos por classe, do conjunto com quatro estímulos por classe e do conjunto com cinco estímulos por classe e médias gerais. 
A Figura 3 apresenta, nas três primeiras linhas, a porcentagem de respostas dos participantes que não estavam de acordo com as classes especificadas pelas experimentadoras (erros); nas três linhas seguintes, o tempo de reação médio das respostas de escolha em segundos e na última linha, a média geral dessas medidas. A primeira, a segunda e a terceira colunas correspondem, respectivamente, aos conjuntos com três, quatro e cinco estímulos por classe. A porcentagem de erros e o tempo de reação são os valores obtidos no Teste Man., em tentativas que testavam relações de linha de base, de simetria e de equivalência. Verifica-se, na Figura 3, que, nove participantes apresentaram as maiores porcentagens de erros quando os conjuntos eram compostos por três estímulos; 11 apresentaram as maiores porcentagens de erros quando os conjuntos eram compostos por quatro estímulos; 15 participantes apresentaram as maiores porcentagens de erros quando os conjuntos eram compostos cinco estímulos. Pode-s observar ainda, tempos de reação médio maiores nas tentativas que envolviam das relações de equivalência. Quando os conjuntos eram compostos por três estímulos, seis participantes apresentaram tempos de reação maiores nas tentativas de teste das relações de equivalência. Quando os conjuntos eram compostos por quatro estímulos, 11 participantes apresentaram tempos de reação maiores nessas tentativas. Quando os conjuntos eram compostos por cinco estímulos, 11 participantes apresentaram tempos de reação maiores nas tentativas de teste das relações de equivalência.

Ainda na Figura 3, não se observam erros no caso de cinco participantes $(12,13,21,31$ e 33$)$ nas tentativas que testaram relações de LB dos conjuntos de classes com cinco estímulos; três participantes $(21,53$ e 62) nas classes com quatro estímulos; e apenas um participante (32) não errou esse tipo de relação quando as classes eram compostas por três estímulos. Ao se analisar as médias gerais de erros, observa-se que são inversamente proporcionais ao número de estímulos por classe diante de todos os tipos de relações. As diferenças nas médias gerais de tempo de reação não são tão acentuadas, variando de 5 a 6 segundos nas relações de linha de base; de 3 a 5 segundos nas relações de simetria; e de 3 a 5 segundos nas relações de equivalência. Apesar da baixa variabilidade desses dados, pode-se observar que quando as classes eram compostas por um maior número de estímulos (quatro ou cinco), o tempo de reação médio é sempre igual ou menor que a respectiva média em uma classe com menos estímulos. Por exemplo, nas tentativas que testaram as relações de equivalência, o tempo de reação médio foi de 6,5 e 5 segundos, respectivamente, em classes formadas por três, quatro ou cinco estímulos.

\section{DISCUSSÃO}

A ordem com que as classes de diferentes tamanhos foram treinadas não produziu efeito estatisticamente significante no desempenho dos participantes. Se tivesse havido efeito dessa variável, a análise dos dados com vistas à demonstração de que o tamanho das classes é uma variável que afeta a manutenção das mesmas teria ter sido inviabilizada. $\mathrm{O}$ efeito da ordem com que as relações condicionais que produziram a emergência de classes com os três diferentes tamanhos de classes foram ensinadas poderia ocorrer porque foi demonstrado anteriormente por Buffington, Fields e Adams (1997) que o pré-treino de classes com diferentes tamanhos tem efeitos distintos sobre a porcentagem de participantes que passam no teste de relações emergentes em uma condição de formação de novas classes de equivalência.

Todos os participantes que concluíram todas as etapas do procedimento atingiram o critério de $90 \%$ de acertos no último Teste Misto de cada conjunto, independente do número de estímulos relacionados nas classes. Nos estudos de Arntzen e Holth (2000), Fields e cols. (1999) e Kato, de Rose, e Faleiros (2008), por exemplo, não foram obtidos índices tão altos de formação de classes de equivalência, o que provavelmente pode ser explicado por diferenças no procedimento de treino e/ou diferenças relativas à topografia das respostas de escolha requeridas. Evidência de que a formação desse tipo de classe é bastante sensível a diversas variáveis podem ser encontradas nos estudos revisados por Barros e cols. (2005), de Rose e cols. (1997) e Moreira e cols. (2006). No presente estudo, quatro aspectos metodológicos possivelmente contribuíram para que esse resultado fosse atingido. O primeiro é o tipo de estrutura de treino usada, que foi a que tem o estímulo de comparação como nódulo $(\mathrm{CaN})$. Com esse tipo de estrutura de treino, o número de nódulos nas classes é mantido constante, sendo sempre um, independente do tamanho das mesmas, o que elimina o efeito diferencial da quantidade de nódulos envolvidos em uma dada relação (Fields \& cols., 1999; Saunders \& Green, 1999). O segundo aspecto está relacionado ao fato de que foi usado o protocolo de treino que vai do simples para o complexo, o qual amplia a possibilidade da formação de classes de equivalência de acordo com Adams e 
cols. (1993). Além disso, a cada conjunto, foram formadas apenas três classes com, no máximo, cinco estímulos, tarefa relativamente fácil em comparação a estudos que planejaram a formação de até seis classes ou de classes com oito estímulos (e.g., Haydu \& Morais, 2005; Saunders \& cols., 1988). O quarto aspecto é a participação de universitários que por serem jovens e adultos sem necessidades especiais, aumentam a probabilidade de formação de classes (Holth \& Arntzen, 2000).

$\mathrm{O}$ índice de repetições dos blocos apresentado pelos participantes, que está relacionado à quantidade de erros durante a etapa de aquisição das relações de LB e das relações emergentes, foi maior no primeiro conjunto de relações condicionais treinadas, para a maioria dos participantes. Entretanto, não há relação entre o índice médio e a porcentagem de acerto no Teste de Man. Esse dado é uma evidência adicional em favor da hipótese de que os resultados obtidos no presente estudo não são função das características pessoais/individuais dos participantes, uma vez que os desempenhos no Teste Man. foram independentes de uma maior dificuldade ou facilidade de cada participante nas etapas de aquisição das relações condicionais.

Os resultados indicam que o número de estímulos por classe é uma variável que contribui para a manutenção das relações, uma vez que um maior número de participantes atingiu o critério no Teste Man., quando as classes eram compostas por cinco estímulos do que quando eram compostas por três ou quatro (oito, seis e três participantes para classes com cinco, quatro e três estímulos respectivamente). Esses resultados corroboram a hipótese de Saunders e cols. (1988) e de Spradlin e cols. (1992) de que o tamanho das classes de equivalência é uma variável que contribui para a manutenção das mesmas, sendo maior a sua probabilidade quanto maior for a classe. Pode-se sugerir, ainda, que provavelmente os dados obtidos por Rocha e Haydu (2002) sejam também evidências em favor dessa hipótese, uma vez que mais de $50 \%$ dos participantes que formaram as classes maiores, em comparação aos que formaram as classes menores, continuaram respondendo de acordo com as classes formadas no primeiro Teste Man. No presente estudo, que envolveu um número maior de participantes em cada conjunto, a diferença entre as classes foi ainda maior. Um aspecto importante que diferencia os dois estudos é o fato de Rocha e Haydu não terem usado um delineamento experimental intra-grupo, o que permite sugerir que os dados por elas obtidos estiveram mais dependentes de variáveis do participante, com, por exemplo, operações motivacionais não controladas experimentalmente.

De acordo com Spencer e Chase (1996) e Tomanari, Sidman, Rubio e Dube (2006), o tempo de reação promove informações adicionais a respeito do desempenho dos participantes. Essas informações referem-se, sobretudo, à diferença no tempo de reação após ter sido observada a estabilidade do comportamento com base no critério de precisão. Spencer e Chase demonstraram que essa variável está relacionada com o tipo de relação testada (simetria, transitividade e equivalência) e que é, também, função do número de nódulos que separam as relações. No presente estudo, o tempo de reação foi maior no Teste Man. do que no Teste Misto; foi maior, também, na manutenção de relações de equivalência do que de linha de base e simetria; e foi maior nas classes com três estímulos do que nas classes com cinco estímulos. Esses dados sugerem que o grau de dificuldade da tarefa foi maior quando os participantes tinham que recordar as relações das classes menores do que das maiores. Os resultados que indicam haver maiores porcentagens de erros e de tempo de reação nas relações de equivalência das classes de diferentes tamanhos, além da maior manutenção das relações de LB das classes maiores, corroboram os resultados de Holth e Arntzen (2000). Estes autores evidenciaram que as relações mais complexas (as de equivalência) são as mais enfraquecidas, o que ocorreu com maior frequência nas classes maiores. Ou seja, nas classes menores, até as relações consideradas menos complexas foram enfraquecidas, enquanto nas maiores predominou o enfraquecimento das relações mais complexas. Esses dados também possibilitam a inferência de que o conjunto em que mais relações de LB se mantiveram intactas beneficiou a recuperação das relações emergentes em classes maiores.

De maneira geral, pode-se concluir que os resultados do presente estudo estão de acordo com a hipótese formulada por Saunders e cols. (1988) e por Spradlin e cols. (1992), uma vez que foi observado que quando as classes eram compostas por um maior número de estímulos, um maior número de participantes manteve o comportamento de responder de acordo com as relações treinadas após o intervalo de 6 semanas. Os resultados indicam, também, que se no planejamento do presente estudo tivessem sido escolhidos apenas dois tamanhos de classes, por exemplo, três e quatro, ou quatro e cinco, o efeito do tamanho das classes poderia não ter sido detectado. Isso permite inferir que o efeito do tamanho das classes de estímulos sobre a sua manutenção, provavelmente, não é linear. Essa pode 
ser uma direção a ser tomada em futuras investigações para responder à questão levantada por Saunders e cols. de quantos estímulos podem ou devem ser relacionados em classes de equivalência, quando se pretende que um determinado conteúdo ensinado tenha maior probabilidade de ser recordado subsequentemente. Obviamente que não se pode afirmar com precisão qual é o limite do tamanho das classes a serem formadas, mas os resultados sugerem que a aprendizagem de classes compostas por mais de quatro estímulos parece ser um ponto de partida.

Os estudos sobre formação e manutenção de classes de estímulos equivalentes parecem elucidar aspectos que levam à compreensão de processos envolvidos no tema que "permanece experimentalmente e, certamente, teoricamente remoto" para os analistas do comportamento que é o da memória (Marr, 1996, p. 89). Entretanto, considera-se que contribuições significativas foram e ainda podem ser feitas para o desenvolvimento de técnicas que auxiliem pessoas com dificuldade de aprendizagem e pessoas que sofrem problemas relacionados ao déficit de memória. Por isso, analisar todas as variáveis que podem interferir na formação e manutenção das classes de equivalência é de grande relevância.

Alguns aspectos requerem investigações adicionais, como, por exemplo, o efeito da ordem com que os participantes formaram as classes de diferentes tamanhos. Essa variável foi controlada no presente estudo e o resultado do tratamento estatístico mostrou que não houve efeito significante. No entanto, a inspeção visual dos dados revela que dos oito participantes que atingiram o critério no conjunto com cinco estímulos por classe, sete eram dos Grupos 1 e 3, havendo, portanto, concentração de participantes que atingiram o critério em dois dos seis grupos. Apesar dessa coincidência, esses grupos foram submetidos a sequências de treino diferentes, o Grupo 1 começou com o treino das classes menores para as maiores (classes com três, quatro e cinco estímulos) e o Grupo 2 das maiores para as menores (classes com cinco, quatro e três estímulos). Esses dados são aparentemente contraditórios e requerem ser esclarecidos. Além dessa questão, outras permanecem em aberto, como, por exemplo, será que o ensino de uma classe, qualquer que seja seu tamanho, facilita o ensino de outra? Ou será que apenas o número de estímulos por classe é relevante para a manutenção das mesmas? Até que ponto a análise do tempo de reação pode ajudar a entender esses aspectos? Enfim, muitos estudos ainda devem ser realizados a fim de que os efeitos das diversas variáveis sejam mais bem compreendidos.

\section{REFERÊNCIAS}

Adams, B. J., Fields, L., \& Verhave, T. (1993). Effects of test order on intersubject variability during equivalence class formation. The Psychological Record, 43(1), 133-152.

Arntzen, E., \& Holth, P. (2000). Probability of stimulus equivalence as a function of class size vs. number of classes. The Psychological Record, 50(1), 79-104.

Barros, R. S., Galvão, O. F., Brino, A. L. F., Goulart, P. R. K., \& McIlvane, W. J. (2005). Variáveis de procedimento na pesquisa sobre classes de equivalência: Contribuições para o estudo do comportamento simbólico. Revista Brasileira de Análise do Comportamento, 1(1), 15-27.

Buffington, D. M., Fields, L., \& Adams, B. J. (1997). Enhancing equivalence class formation by pretraining of equivalence classes. The Psychological Record, 47(1), 69-96.

Carmo, J. S., Silva, L. C. C., \& Figueiredo, R. M. E. (Orgs.). (1999). Dificuldades de aprendizagem no ensino de leitura, escrita e conceitos matemáticos. Belém: Unama.

de Rose, J. C., Kato, O. M., Thé, A. P. G., \& Kledaras, J. B. (1997). Variáveis que afetam a formação de classes de estímulos: Estudos sobre efeitos do arranjo de treino. Acta Comportamentalia, 5(2), 143-163.

de Rose, J. C., Souza, D. G., \& Hanna, E. S. (1996). Teaching reading and spelling: Exclusion and stimulus equivalence. Journal of Applied Behavior Analysis, 29(4), 451-469.

Fields, L., Hobbie-Reeve, S. A., Adams, B. J., \& Reeve, K. F. (1999). Effects of training directionality and class size on equivalence class formation by adults. The Psychological Record, 49(4), 703-724.

Fields, L., Reeve, K. F., Rosen, D., Varelas, A., Adams, B. J., Belanich, J., \& Reeve, S. A. (1997). Using the simultaneous protocol to study equivalence class formation: The facilitating effects of nodal number and size of previously established equivalence classes. Journal of Experimental Analysis of Behavior, 67(3), 367-389.

Haydu, V. B., \& de Paula, J. B. C. (2005). Estabilidade de equivalência de estímulos: Efeito do número de tentativas de treino e do tamanho das classes. Em Departamento de Psicologia da UEM (Org.), Anais do II Congresso Internacional e VII Semana de Psicologia (pp. 1-16). Maringá: UEM.

Haydu, V. B., \& Morais, L. P. (2005). Formação e manutenção de classes de estímulos equivalentes de diferentes tamanhos: Um estudo com adultos da terceira idade. Em Departamento de Psicologia da UEM (Org.), Anais do II Congresso Internacional e VII Semana de Psicologia (pp. 1-15). Maringá: UEM.

Holth, P., \& Arntzen, E. (2000). Reaction times and the emergence of class consistent responding: A case for precurrent responding? The Psychological Record, 50(2), 305-337.

Kato, O. M., de Rose, J. C., \& Faleiros, P. B. (2008). Topography of responses in conditional discrimination influences formation of equivalence classes. The Psychological Record, 58(2), 245267.

Marr, J. (1996). Method and theory in memory: Or, how many rooms are there in the Mad Hatter's house? The Behavior Analyst, 19(1), 89-90.

Matos, M. A., Hübner, M. M., Serra, V. R. B., Basaglia, A. E., \& Avanzi, A. L. (2002). Redes de relações condicionais e leitura recombinativa: Pesquisando o ensinar a ler. Arquivos Brasileiros de Psicologia, 54(2), 284-303. 
Medeiros, J. G., Vettorazi, A., Kliemann, A., Kurban, L., \& Mateus, M. S. (2007). Emergência conjunta dos comportamentos de ler e escrever palavras e identificar números após o ensino em separado desses repertórios. Psicologia Ciência e Profissão, 27(1), 4-21.

Moreira, M. B., Todorov, J. C., \& Nalini, L. E. G. (2006). Considerações sobre o responder relacional. Revista Brasileira de Terapia Comportamental Cognitiva, 8(2), 192-211.

Rehfeldt, R. A., \& Dixon, M. R. (2005). Evaluating the establishment and maintenance of visual-visual and gustatory-visual equivalence relations in adults with developmental disabilities. Behavior Modification, 29(4), 696-707.

Rehfeldt, R. A., \& Dymond, S. (2005). The effects of test order and nodal distance on the emergence and stability of derived discriminative stimulus functions. The Psychological Record, 55(2), 179-196.

Rehfeldt, R. A., \& Root, S. (2004). The generalization and retention of equivalence relations in adults with mental retardation. The Psychological Record, 54(2), 173-186.

Rocha, M. M., \& Haydu, V. B. (2002). O efeito do número de membros das classes na formação e manutenção da equivalência de estímulos: Implicações para o desenvolvimento de estratégias de ensino. Em Sociedade Brasileira de Psicologia (Org.), Resumos de Comunicação Científica, XXXII Reunião Anual de Psicologia (pp. 97). Florianópolis: SBP.

Saunders, R. R., Wachter, J., \& Spradlin, J., E. (1988). Establishing auditory stimulus control over an eight-member equivalence class via conditional discrimination procedure. Journal of the Experimental Analysis of Behavior, 49(1), 95-115.

Saunders, R. R., \& Green, G. (1999). A discrimination analysis of training-structure effects on stimulus equivalence outcomes. Journal of the Experimental Analysis of Behavior, 72(1), 117137.

Sidman, M. (1971). Reading and auditory-visual equivalence. Journal of Speech and Hearing Research, 14(1), 5-13.
Sidman, M. (1994). Equivalence relations: A research story. Boston: Authors Cooperative.

Sidman, M., \& Cresson, O. (1973). Reading and crossmodal transfer of stimulus equivalence in severe retardation. American Journal of Mental Deficiency, 77, 515-523.

Souza, R. D. C., \& Assis, G. J. A. (2005). Emergência de relações numéricas sob controle condicional em crianças surdas. Psicologia: Teoria e Pesquisa, 21(3), 297-308.

Spencer, T. J., \& Chase, P. N. (1996). Speed analysis of stimulus equivalence. Journal of the Experimental Analysis of Behavior, 65(3), 643-659.

Spradlin, J. E., Cotter, V. W., \& Baxley, N. (1973). Establishing a conditional discrimination without direct training: A study of transfer with retarded adolescents. American Journal of Mental Deficiency, 77(5), 556-566.

Spradlin, J. E., Saunders, K. J., \& Saunders, R. R. (1992). The stability of equivalence classes. Em S. C. Hayes \& L. J. Hayes. (Orgs.), Understanding verbal relations: The second and third international institute on verbal relations (pp. 29-42). Reno: Context Press.

Stromer, R., Mackay, H. A., \& Stoddard, L. T. (1992). Classroom applications of stimulus equivalence technology. Journal of Behavioral Education, 2(3), 225-256.

Tomanari, G. Y., Sidman, M., Rubio, A. R., \& Dube, W. V. (2006). Equivalence classes with requirements for short response latencies. Journal of the Experimental Analysis of Behavior, 85(3), 349-369.

Wirth, O., \& Chase, P. N. (2002). Stability of functional equivalence and stimulus equivalence: Effects of baseline reversals. Journal of the Experimental Analysis of Behavior, 77(1), 29-47.

Recebido: 08/10/2008

Última revisão: 11/09/2009 Aceite final: 29/09/2009

\footnotetext{
Nota:

${ }^{1}$ Este estudo foi possível graças ao apoio do Conselho Nacional de Desenvolvimento Científico e Tecnológico (CNPq) e da PROPPG da Universidade Estadual de Londrina.
}

\section{Sobre as autoras:}

Verônica Bender Haydu: Doutora em Psicologia Experimental pela Universidade de São Paulo. Docente do Departamento de Psicologia Geral e Análise do Comportamento da Universidade Estadual de Londrina, UEL.

Leila Cristina Ferreira Omote: Graduada em Psicologia pela Universidade Estadual de Londrina. Departamento de Psicologia Geral e Análise do Comportamento da Universidade Estadual de Londrina.

Priscila Vicente: Mestranda em Análise do Comportamento pela Universidade Estadual de Londrina. Departamento de Psicologia Geral e Análise do Comportamento da Universidade Estadual de Londrina.

Natalia Maria Aggio: Mestranda em Psicologia pela Universidade Federal de São Carlos. Departamento de Psicologia Geral e Análise do Comportamento da Universidade Estadual de Londrina.

Juliana Barboza Caetano de Paula: Mestranda em Análise do Comportamento pela Universidade Estadual de Londrina. Departamento de Psicologia Geral e Análise do Comportamento da Universidade Estadual de Londrina.

Endereço para correspondência: Verônica Bender Haydu - Departamento de Psicologia Geral e Análise do Comportamento, Universidade Estadual de Londrina - Rodovia Celso Garcia Cid, PR 445, KM 380, Caixa Postal 6001 - 86051-990 - Londrina/PR - Endereço eletrônico: haydu@uel.br. 